\title{
Effects of crowding and sex on fecal cortisol levels of captive forest musk deer
}

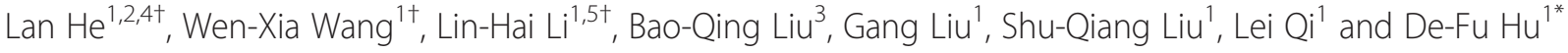

\begin{abstract}
Background: Restricted space and close contact with conspecifics in captivity may be stressful for musk deer, as they are highly territorial and solitary in the wild. So we tested the effects of crowding on stress of forest musk deer (Moschus berezovskii) in heterosexual groups, using fecal cortisol analysis as a non-invasive method. 32 healthy adults during non-breeding seasons were chose as our experimental objects. Group 1 was defined as higher crowding condition, with 10-15 $\mathrm{m}^{2} /$ deer ( 6 enclosures, 109 and 63 ); group 2 was defined as lower crowding condition, with 23-33 $\mathrm{m}^{2} /$ deer ( 6 enclosures, 109 and $60^{1}$ ). Every enclosure contained 1 male and 3 female. These patterns had been existed for years.

Results: The results showed that females in lower crowding condition $(217.1 \pm 9.5 \mathrm{ug} / \mathrm{g})$ had significantly higher fecal cortisol levels than those in higher crowding condition (177.2 $\pm 12.1 \mathrm{ug} / \mathrm{g})$. Interestingly, crowding seemed have no effect on male fecal cortisol levels (148.1 $\pm 9.1 \mathrm{ug} / \mathrm{g}$ and $140.5 \pm 13.3 \mathrm{ug} / \mathrm{g}$, respectively). At both groups, cortisol was significantly lower in males than in females.
\end{abstract}

Conclusions: These results showed that chronic crowding may affect stress status of captive forest musk deer. The captive environment should consider the space need for musk deer.

Keywords: Captivity, M. berezovskii, Fecal cortisol, Chronic stress, Crowding

\section{Background}

Captive breeding is an important tool for conservation of endangered wild animals. However, potential stressors in the captive environment are numerous, and their effects are often species-specific [1,2]. Captive animals are likely suffering chronic stress [3], resulting from lack of space, abnormal social groups and/or other restrictions to the animals' natural behavioral needs [4]. Chronic stress may cause physiological and psychiatric disorders $[5,6]$, and decreased immunity $[7,8]$. So it's very important to assess and identify the main stressors for effective population management and the ultimate success of captive breeding programs.

Musk deer (Moschus spp.) are small solitary ungulates distributed throughout forested and mountainous parts of Asia. They are world-famous because male musk deer

\footnotetext{
* Correspondence: hudf@bjfu.edu.cn

${ }^{\dagger}$ Equal contributors

'Laboratory of Non-invasive Research Technology for Endangered Species, College of Nature Conservation, Beijing Forestry University, No. 35 Tsinghua East Road, Haidian District, Beijing 100083, China

Full list of author information is available at the end of the article
}

secrete musk from the musk gland, located between their naval and genitals [9-11]. Musk has been used in Chinese traditional medicine for over 2000 years, and use in expensive perfume material in the European countries due to its permanent and special scent. Currently, captivity has become the main methods to conserve musk deer, since their wild population is almost exhausted. However, their captive populations grow slowly. Although it's generally considered that musk deer is difficult to be captive because of their timid and alert characteristics, these characteristics easily cause stress responses. But there are yet no studies about relationships between captive environment and stress status of musk deer. Since 2003, China drawn up "the Conservation Plan of Musk deer", in which, establishing large scale of captive population is one of the main objects. Undoubtedly, lack of this information will affect the establishing of breeding population and formulating reasonable measures of the management.

Crowding is a common stressor in captive environment [4]. Crowding (means restricted space and close social contact) may be much stressful for musk deer, 
since they are solitary and territory animals in the wild; however no relative experiments have been reported.

Here, we used a non-invasive method to test the relationship between captive environment and stress status of forest musk deer ( $M$. berezovskii), one of the main captive species of musk deer in China, in order to help understanding the reason of difficult population development in musk deer, and improving welfare and conservation of these animals.

The objectives of this study were to (1) test whether different crowding condition (which means restricted space and close contact with conspecifics) affect fecal cortisol concentration (FCC) of musk deer; (2) test whether female and male musk deer response differently to crowding conditions, when they are reared in heterosexual groups.

\section{Results}

Only 4 individuals had extreme FCC that was 2SD above baseline, two were the female in group 1, one was the female in group 2, and one was the male in group 2 (Tables 1 and 2), these values were excluded and baselines were recalculated. The FCC fluctuated, but most values were within $95 \%$ confident interval. The

Table 1 The highest and lowest value, variation range, and standard errors of female FCC $(n=20)$

\begin{tabular}{|c|c|c|c|c|c|}
\hline & $\begin{array}{c}\text { Musk } \\
\text { deer }\end{array}$ & $\begin{array}{l}\text { Highest } \\
\text { FCC } \\
\text { (ug/g) }\end{array}$ & $\begin{array}{c}\text { Lowest } \\
\text { FCC } \\
\text { (ug/g) }\end{array}$ & $\begin{array}{c}\text { Variation } \\
\text { range of } \\
\text { FCC (ug/g) }\end{array}$ & $\begin{array}{c}\text { Standard } \\
\text { error }\end{array}$ \\
\hline \multirow{9}{*}{$\begin{array}{l}\text { Higher } \\
\text { crowding }\end{array}$} & 1 & 145.6 & 121.7 & 23.9 & 3.0 \\
\hline & 2 & 179.1 & 128.9 & 50.2 & 6.3 \\
\hline & 3 & $273.7^{*}$ & 177.6 & 96.1 & 12.2 \\
\hline & 4 & $268.4^{*}$ & 190.2 & 78.2 & 23.3 \\
\hline & 5 & 186.3 & 133.8 & 52.5 & 6.1 \\
\hline & 6 & 236.8 & 135.5 & 101.3 & 12.0 \\
\hline & 7 & 193.8 & 153.9 & 39.9 & 5.6 \\
\hline & 8 & 232.4 & 167.2 & 65.2 & 9.1 \\
\hline & 9 & 226.2 & 169.6 & 56.6 & 8.2 \\
\hline \multirow{11}{*}{$\begin{array}{l}\text { Lower } \\
\text { crowding }\end{array}$} & 10 & 211.7 & 170.8 & 40.9 & 6.3 \\
\hline & 1 & 239.4 & 165.6 & 73.8 & 9.5 \\
\hline & 2 & $319.9^{*}$ & 208.4 & 111.5 & 14.0 \\
\hline & 3 & 296.5 & 181.6 & 114.9 & 14.2 \\
\hline & 4 & 206.8 & 181.0 & 25.8 & 4.0 \\
\hline & 5 & 249.7 & 185.4 & 64.3 & 8.3 \\
\hline & 6 & 252.4 & 175.6 & 76.8 & 10.6 \\
\hline & 7 & 265.9 & 169.9 & 96.0 & 12.9 \\
\hline & 8 & 285.5 & 194.4 & 91.1 & 12.0 \\
\hline & 9 & 241.8 & 195.8 & 46.0 & 6.5 \\
\hline & 10 & 230.8 & 175.7 & 55.1 & 7.3 \\
\hline
\end{tabular}

Note: *represent values that 2SD above the baseline.
Table 2 The highest and lowest value, variation range, and standard errors of male FCC $(n=12)$

\begin{tabular}{cccccc}
\hline & $\begin{array}{c}\text { Musk } \\
\text { deer }\end{array}$ & $\begin{array}{c}\text { Highest } \\
\text { FCC } \\
\text { (ug/g) }\end{array}$ & $\begin{array}{c}\text { Lowest } \\
\text { FCC } \\
\text { (ug/g) }\end{array}$ & $\begin{array}{c}\text { Variation } \\
\text { range of } \\
\text { FCC (ug/g) }\end{array}$ & $\begin{array}{c}\text { Standard } \\
\text { error }\end{array}$ \\
\hline \multirow{4}{*}{ Higher crowding } & 1 & 157.1 & 123.1 & 34.0 & 8.5 \\
& 2 & 180.0 & 116.0 & 64.0 & 7.9 \\
& 3 & 166.5 & 122.2 & 44.3 & 6.8 \\
& 4 & 184.8 & 134.4 & 50.4 & 6.6 \\
& 5 & 179.6 & 108.8 & 70.8 & 9.6 \\
& 6 & 187.7 & 125.4 & 62.3 & 8.9 \\
& 1 & 181.5 & 109.0 & 72.5 & 11.9 \\
& 2 & 180.7 & 114.8 & 65.9 & 7.8 \\
& 3 & 194.3 & 110.9 & 83.4 & 10.2 \\
& 4 & 192.8 & 114.3 & 78.5 & 12.6 \\
& 5 & 170.9 & 94.3 & 76.6 & 9.5 \\
& 6 & $212.3^{*}$ & 115.9 & 96.4 & 12.3 \\
\hline
\end{tabular}

Note: *represent values that are $2 \mathrm{SD}$ above the baseline.

ranges of FCC changed from 23.9 to $101.3 \mathrm{ug} / \mathrm{g}, 25.8$ to $114.9 \mathrm{ug} / \mathrm{g}$ for females reared in higher and lower crowding conditions, respectively (Table 1). And the FCC ranges changed from 34.0 to $70.8 \mathrm{ug} / \mathrm{g}, 65.9$ to $96.4 \mathrm{ug} / \mathrm{g}$ for males reared in higher and lower crowding conditions, respectively (Table 2).

For the mean baseline values, FCC of females reared in group 1 was $177.2 \mathrm{ug} / \mathrm{g}$, which was significantly lower than that of the group 2, 217. $1 \mathrm{ug} / \mathrm{g}$ (Figure 1) $(t=-2.599$,

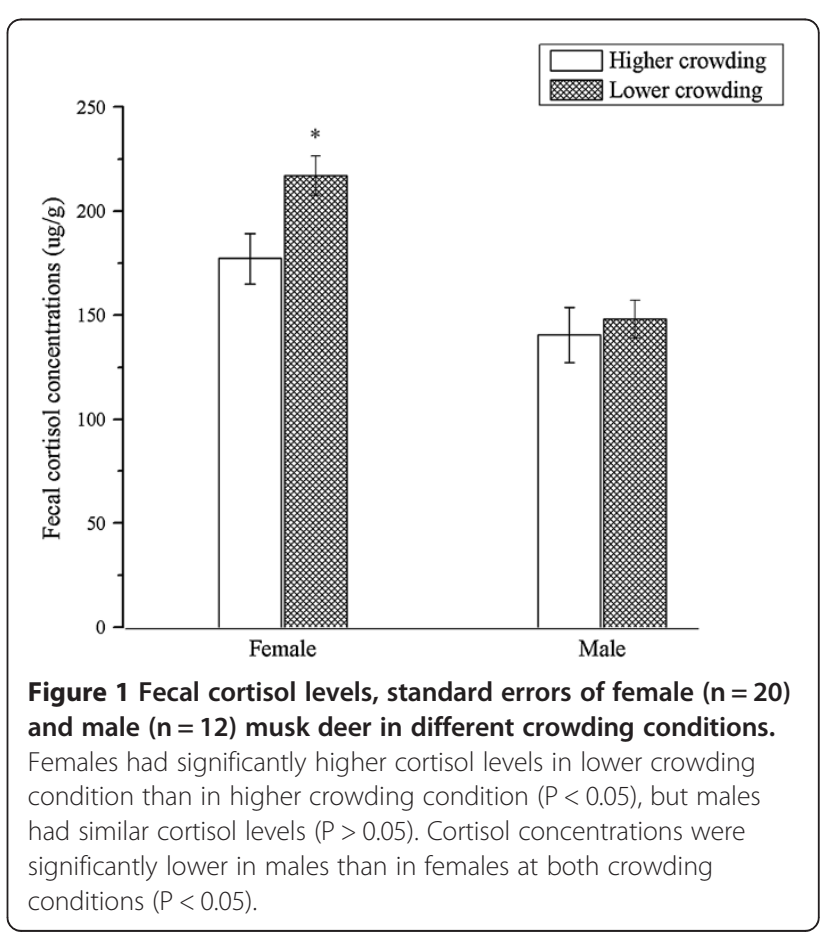


$\mathrm{P}=0.018$ ). But for males, $\mathrm{FCC}$ were $148.1 \mathrm{ug} / \mathrm{g}$ and $140.5 \mathrm{ug} / \mathrm{g}$ in group 1 and group 2 respectively, without significant differences (Figure 1) $(\mathrm{t}=0.468, \mathrm{P}=0.650)$.

There was significantly differences when take sex into account. FCC of females was $19.9 \%$ and $54.5 \%$ higher than that of the male musk deer reared in higher and lower crowding conditions, respectively $(t=2.719, \mathrm{P}=0.017$; $\mathrm{t}=4.794, \mathrm{P}=0.000$ ) (Figure 1).

\section{Discussions}

\section{Effect of chronic crowding stress}

Captive environment is much different than wild environment, thus it would potentially stressed captive animals. There are many stressors in captive environment [4], and stress effect may be existing even when animals are reared in captivity for many generations [12]. Crowding is one of the most important stressors in captive environment, which means less space and close contact with conspecifics. Most studies reported higher glucocorticoid levels according to crowding. For example, plasma cortisol levels of non-human primate in crowding groups were significantly higher than paired individuals [13-15]. Li et al. [16] found that changes from large enclosures to small pens resulted in higher level of cortisol secretion in Pe're David's deer (Elaphurus davidianus).

However, in this study, compared with less crowding condition (217.1 ug/g), female musk deer housed in higher crowding condition $(177.2 \mathrm{ug} / \mathrm{g})$ had significantly lower FCC (Figure 1). These inconsistent glucocorticoid responses to crowding may due to different stress time, and different personality of species-different species may responses to the same stressors differently $[1,2]$. Forest musk deer are territory, solitary, shy, and timid mammals in the wild [11,17]. However, in captivity, they are compelled to be housed with each other in an enclosure that is 40 to $132 \mathrm{~m}^{2}$. No doubt that the increased social contact and decreased space were stressful for such solitary and shy animals. What's more, forest musk deer like jumping and running, that's their survival strategies evolved in the wild. However, the captive space is too small to exhibit this behavior, and they developed stereotyped behavior (such as repeated walk back and forth, constant jump up and down). Our investigation in other breeding centers show that forest musk deer in semi-free captive environment (more natural environment, larger space that is about $660 \mathrm{~m}^{2}$ and about $200-300 \mathrm{~m}^{2}$ per deer) have significantly lower stereotyped behavior than those in captive environment (certainly, the stereotyped behaviors did not disappeared). And we found that, adults in semi-free captive environment have less disease, such as diarrhea, dyspepsia, and abscess disease (unpublished data). Liu et al. [18] also reported that diseases of forest musk deer decreased when they were reared in natural enclosures (about $400 \mathrm{~m}^{2}$ ). In this study, the rearing pattern is one male with three female musk deer, the decreased cortisol levels of musk deer might be the response to close contact with conspecifics and lack of home range, which might become chronic stress as time passed.

Miller et al. [19] reviewed that chronic stress will cause both increase and decrease of glucocorticoid levels. Shortly after the stress has begun, the hypothalamic-pituitaryadrenal axis may become activated, resulting in elevated corticoid output. However, with the passage of time, the body could mount a counter-regulatory response such that corticoid output rebounds below normal [19]. Recently, many researchers found the decreased glucocorticoid levels in captive or wild animals. For example, in free-living and wild-caught European starlings (Sturnus vulgaris) exposed to an experimental chronic stress consisting of unpredictable, and different rotating stressors, both baseline and stress-induced corticosterone are suppressed $[20,21]$, and sensitivity of the pituitary and adrenal gland are altered [19]. Linklater et al. [22] also suggested that captivity results decline of fecal corticoid levels in rhinoceros after translocation. In our study, the decreased cortisol levels of the captive forest musk deer may reflect the end stage of stress-because all of the experimental musk deer have been captive reared since they were born, such long time may bring them into the end status of the chronic stress.

An interesting but inexplicable phenomenon is that crowding seems don't affect stress of male forest musk deer, because males in both groups had similar FCC. One possibility is that male musk deer are highly stressed under captive environment, which might cover the crowding effect. Much more has been discussed below.

\section{Sex difference of cortisol levels in heterosexual groups}

In our study, crowding environment means less space and close social contact with conspecifics. Animals cope with social contact differently according to group type, group size, and gender. Our study show an apparently different cortisol levels in different sexes, males had significantly lower FCC than females (19.9\% and 54.5\% higher in female than in male). Sex differences in adrenocortical activity are not uncommon in other mammals. For example, female North American clouded leopards (Neofelis nebulosa) and female mouse lemur (Microcebus murinus) had significantly higher corticoid levels than males [15,23]. Other studies about glucocorticoid levels in rodents and humans according to gender are inconsistent. For example, adrenal weight is greater in the male hamster than in the female [24]. However, other studies about rats showed that corticosterone concentration were higher in female than male rats $[25,26]$. These sex differences may due to different gonadal hormone effect [27-30], and glucocorticoid receptor and binding protein levels [30,31]. The sex differences may reflect underlying differences in 
steroid metabolism, excretion routes, and pituitary responsiveness [32].

However, in this study, the sex differences about cortisol levels in forest musk deer might reflect different stress status. Many studies about rodent and humans show that the female can influence male's behavior and physiology [33,34]. Naturally, musk deer are solitary, even the female and male musk deer encounter and stay with each other briefly only during breeding seasons, and they separate and return to their own territories as soon as mating succeeded/ended [11]. In captivity, several male forest musk deer are reared together with several females in an enclosure (in our study, the rearing pattern is one male with three female), all the year round. Such unnatural environment may cause chronic stress; female musk deer may enhance the stress of male individuals. Our investigation show that, when the male and the female forest musk deer are reared separately during the non-breeding season-several males live together in an enclosure without see each other (everyone has an individual house), and are allowed by turns to play and move in the outside yard. Their fecal cortisol levels are similar with females at the non-breeding seasons. So it could be speculated that, the long-term exist of female musk deer might enhance the stress of males, leads to lower cortisol levels in the males. It seems to explain, at least part of, the reasons of higher mortality in the male than in the female forest musk deer ([35], and our unpublished data). And during the mating seasons, many centers lack the seed breeding male forest musk deer (our surveys), which might be the results of chronic captive stress. Fortunately, in recent years, some centers began semi-free rearing practices, which may improve welfare of musk deer.

However, other ungulates, such as red deer (Cervus elaphus), did not found significant differences between sexes [36]; but they performed the study on an undisturbed red deer herd, kept in a 45-ha enclosure. While in our study, the forest musk deer are captive in an environment with restricted space (only less than $132 \mathrm{~m}^{2}$ ). What's more, red deer is social species, while forest musk deer is solitary animals. In the captive environment, however, they are compelled to live with conspecifics. Such unnatural environments may induce highly stress.

It's a pity that we did not collect wild feces of forest musk deer, and we do not know the actual stress status of forest musk deer in the wild. So the relationship of stress status of forest musk deer between the captive and wild conditions should be further studied. Furthermore, although female musk deer lived in lower crowding condition had higher cortisol levels, but we could not determine that these individuals are comfortable. It' should be pointed out that in this study, we defined the crowding degree as relative higher and lower, because we yet do not know the threshold of un-crowding conditions.

\section{Conclusions}

In sum, we suggest that crowding condition may affect stress of forest musk deer. Though we yet do not know which the best environment for captive musk deer is, but it's certain that too small captive environment is not suitable for the welfare of musk deer. The current enclosure designs may be too small to satisfy their natural need. And we also suggest that, the rearing patterns of heterosexual group might not be appropriate, long-term of stimulation by the females might enhance stress of males. So the future management should consider the space need and the group component.

\section{Methods}

\section{Study site and animals}

The study was conducted at Breeding Center of Forest Musk Deer, located in Fengxian, Shanxi Province, a region of Qing Ling Mountain $\left(33^{\circ}-34^{\circ} \mathrm{N}, 106^{\circ}-107^{\circ} \mathrm{E}\right)$. The region is in a warm temperate zone, with an annual average temperature of $11.4^{\circ} \mathrm{C}$ and annual average rainfall of 613.2-897.1 $\mathrm{mm}$.

From April to September is the non-breeding season [11,37]. All animals were fed twice per day, at dawn and dusk, with fresh leaves (in summer and autumn) or dried leaves (in winter and spring), which were collected from the natural habitat of wild musk deer. The plants include nutgall (Anacardiaceae rhus), Chinaberry seed (Simaroubaceae picrasma), elm (Ulmus pumila), etc. Supplementary artificial food mainly consisted of flour, wheat bran and some seasonal vegetables. Water was provided ad libitum.

One male with three female musk deer (Moschus berezovskii) were kept in an enclosure which consisted of an outdoor yard, and lined several brick houses, the total area of each enclosure is about $40-132 \mathrm{~m}^{2}$. All the male and females in an enclosure can move and play in the yard during the day; they were kept individually in each individual house during the night. These group patterns have been exist for years in this breeding center.

We define the average space of $10-15 \mathrm{~m}^{2}$ per individual as group1 (higher crowding condition), and the average space of $23-33 \mathrm{~m}^{2}$ per individual as group 2 (lower crowding condition). The two groups contains 6 enclosures respectively, each group contain 6 males and 10 females. All the animals were healthy adults aged 3-7 years, and both were captive, without wild-caught animals.

\section{Sample collection}

The samplings were conducted during August to September in 2011. This period is non-breeding season, although the farmers reared the female and male forest musk deer together as in breeding season. This period also is the period of delactation (offspring are separated from mothers). We chose this period to avoid other stressors, such as mating, rearing and protecting offspring. 
Feces were collected every other day for each subject for two weeks. Every afternoon at 19:00-20:00 P.M, the raiser cleaned feces out of the individual house, so we can collect fresh feces (defecate during the night) for each individual at the next morning. The feces were collected at 6:00 to 8:00 A.M. and stored frozen at $-20^{\circ} \mathrm{C}$ immediately after collection. The Sampling collection was carried out by the raiser instead of the researchers in order to decrease stress response.

The fecal sampling (non-invasive method) was carried out under the authority of a scientific permit issued by Shanxi Forestry Bureau, Shanxi, China. Our sampling method is non-invasive, that we only collected animal's feces.

\section{Fecal cortisol extraction and determination}

Fecal cortisol was extracted as previously described with little changes [37]. Briefly, frozen samples were thawed at the room temperature, and the feces were homogenized in a grinder. Then, $0.5 \mathrm{~g}$ of feces was mixed with 5 $\mathrm{ml}$ of $90 \%$ methanol in a $15-\mathrm{ml}$ glass tube and extracted using a "water bath" at $60^{\circ} \mathrm{C}$ for $20 \mathrm{~min}$. All tubes were then centrifuged at $2500 \mathrm{rpm}$ for $20 \mathrm{~min}$ and the supernatant was recovered. An additional $5 \mathrm{ml}$ of $90 \%$ methanol was added to the fecal pellet, which was then vortexed for $1 \mathrm{~min}$. and centrifuged at $2500 \mathrm{rpm}$ for $15 \mathrm{~min}$. The supernatants were recovered. The combined supernatants were dried, re-dissolved in $1 \mathrm{ml}$ methanol and the solution was kept at $-20^{\circ} \mathrm{C}$ until assayed.

Fecal cortisol quantitative diagnostic kits were obtained from Shanghai Yueyan Biological Technology Co., Ltd., Shanghai, China. The assays were performed according to the manufacturer's directions. Sensitivity parameters are as followers, sensitivity is $\leq 5.0 \mathrm{ug} / \mathrm{ml}$, intra-assay $\mathrm{CV}$ is $<7 \%$ and the inter-assay $\mathrm{CV}$ is $<8.5 \%$, no cross reaction.

For each feces, water content was calculated (dry in the oven at $65^{\circ} \mathrm{C}$ for $8 \mathrm{~h}$ ) and was used to adjust the final fecal cortisol concentrations (FCC), so the unit of the FCC was transformed from $\mathrm{ug} / \mathrm{ml}$ to $\mathrm{ug} / \mathrm{g}$.

\section{Data analysis}

FCC is reported as the baseline mean \pm standard error of the mean. Individual baseline means were calculated for each animal using an iteration process where all peak values two standard deviations above the mean were excluded and means were recalculated until extreme values were excluded [38].

Assumptions of normality were checked by examining normal probability plots and calculating a KolmogorovSmirnov statistic. An independent-samples t-test was used to analyze sex and crowding effects. For all analyses, significance was set at the 0.05 level. Statistical analyses were conducted using SPSS Version 18.0 for Windows. Figure was drawn using Origin 8.0.
Competing interests

The authors declare that they have no competing interests.

\section{Authors' contributions}

$\mathrm{LH}$ and WXW carried out the sample collection, hormone detection, data analysis and drafted the manuscript. LHL participated in the design of the study and carried out the data analysis and drafted the manuscript.

GL participated in the design of the study and carried out same collection. BQL participated in the sample collection and data analysis. SQL and LQ participated in the design of the study and performed the statistical analysis. DFH, who is the corresponding author, conceived of the study and participated in its design and coordination and helped to draft the manuscript. All authors read and approved the final manuscript.

\section{Acknowledgements}

We thank the Breeding Center of Forest musk deer in Shanxi Province, and Mr. Shu-min Chen for their help and support. This work was financed by Species Salvation Program of Department of Fauna and Flora and Nature Reserve Management, State Forestry Administration of China (No. musk deer 2013).

\section{Author details}

${ }^{1}$ Laboratory of Non-invasive Research Technology for Endangered Species, College of Nature Conservation, Beijing Forestry University, No. 35 Tsinghua East Road, Haidian District, Beijing 100083, China. ${ }^{2}$ Key Laboratory of Species Diversity Application and Control in Xinjiang, Urumqi, Xinjiang Normal Univesity, Xinjiang 830054, China. ${ }^{3}$ Breeding Centre of Forest Musk Deer in Pientzehuang, Baoji 721000, China. ${ }^{4}$ Present address: Xinjiang Normal University, NO.102, the Xinyi Road, Urumqi, Xinjiang 830054, China. ${ }^{5}$ Present address: Beijing Natural History Museum, No.126, the South Street, Dongcheng District, Beinjing 100050, China.

Received: 23 July 2014 Accepted: 12 September 2014

Published: 29 September 2014

\section{References}

1. Dickens MJ, Delehanty DJ, Michael Romero L: Stress: an inevitable component of animal translocation. Biol Conserv 2010, 143(6):1329-1341.

2. Mason GJ: Species differences in responses to captivity: stress, welfare and the comparative method. Trends Ecol Evol 2010, 25(12):713-721.

3. Manning A, Dawkins MS: An Introduction to Animal Behaviour. Cambridge: Cambridge University Press; 1998.

4. Morgan KN, Tromborg CT: Sources of stress in captivity. Appl Anim Behav Sci 2007, 102(3-4):262-302.

5. Mcewen BS: Protection and damage from acute and chronic stress: allostasis and allostatic overload and relevance to the pathophysiology of psychiatric disorders. Ann NY Acad Sci 2004, 1032(1):1-7.

6. Teixeira CP, De Azevedo CS, Mendl M, Cipreste CF, Young RJ: Revisiting translocation and reintroduction programmes: the importance of considering stress. Anim Behav 2007, 73(1):1-13.

7. Dhabhar FS, MCewen BS: Acute stress enhances while chronic stress suppresses cell-mediated immunity in vivo: a potential role for leukocyte trafficking. Brain Behav Immun 1997, 11(4):286-306.

8. Gouin JP, Hantsoo L, Kiecolt-Glaster JK: Immune dysregulation and chronic stress among older adults: a review. Neuroimmunomodulat 2008, 15(4-6):251-259.

9. Green MJ: The distribution, status and conservation of the Himalayan musk deer (Moschus chrysogaster). Biol Conserv 1986, 35(4):347-375.

10. Green M: Scent-marking in the Himalayan musk deer (Moschus chrysogaster). J Zool Series B 1987, 1(4):721-737.

11. Sheng HL, Liu ZX: The musk Deer in China. Shanghai: The Shanghai Scientific \& Technical Publishers; 2007.

12. Mason GJ, Cooper J, Clarebrough C: Frustrations of fur-farmed mink. Nature 2001, 410(6824):35-36.

13. Sassenrath $\mathrm{E}$ : Increased adrenal responsiveness related to social stress in rhesus monkeys Horm. Behav 1970, 1(4):283-298.

14. Mendoza SP, Coe CL, Lowere EL, Levine S: The physiological response to group formation in adult male squirrel monkeys. Psychoneuroendocrinology 1978, 3(3):221-229.

15. Perret $M$, Predine J: Effects of long-term grouping on serum cortisol levels in Microcebus murinus (Prosimii). Horm Behav 1984, 18(3):346-358. 
16. Li C, Jiang Z, Tang S, Zeng Y: Influence of enclosure size and animal density on fecal cortisol concentration and aggression in Pere David's deer stags. Gen Comp Eendocr 2007, 151(2):202-209.

17. Sheng HL, Xu HF, Lu HJ: Territory and habitat selection of forest musk deer. J East China Normal University (Natural Science) Album of Mammalian Ecology 1990, 14-19.

18. Liu WH, Wang YQ, Li FR, Tang J, Yang Z: A primary study on breeding the musk deer by enclosure culture in Qinling Mountains. J Economic Anim 2010, 14(2):63-66.

19. Miller GE, Chen E, Zhou ES: If it goes up, must it come down? Chronic stress and the hypothalamic-pituitary-adrenocortical axis in humans. Psychol Bull 2007, 133(1):25.

20. Rich EL, Romero LM: Exposure to chronic stress downregulates corticosterone responses to acute stressors. Am J Physiol-Reg I 2005, 288(6):R1628-R1636.

21. Cyr NE, Michael RL: Chronic stress in free-living European starlings reduces corticosterone concentrations and reproductive success. Gen Comp Endocr 2007, 151(1):82-89.

22. Linklater W, Macdonald E, Flamand J, Czekala N: Declining and lower fecal corticoids are associated with distress, not acclimation to stress, during the translocation of African rhinoceros. Anim Conserv 2010, 13(1):104-111.

23. Wielebnowski NC, Fletchall N, Carlstead K, Busso JM, Brown JL: Noninvasive assessment of adrenal activity associated with husbandry and behavioral factors in the North American clouded leopard population. Zoo Biol 2002, 21(1):77-98.

24. Gaskin JH, Kitay Jl: Adrenocortical function in the hamster: sex differences and effects of gonadal hormones. Endocrinology 1970, 87(4):779-786.

25. Mitsushima D, Masuda J, Kimura F: Sex differences in the stress-induced release of acetylcholine in the hippocampus and corticosterone from the adrenal cortex in rats. Neuroendocrinology 2003, 78(4):234-240.

26. Kitay Jl: Sex differences in adrenal cortical secretion in the rat. Endocrinology 1961, 68(5):818-824.

27. Handa RJ, Burgess LH, Kerr JE, O'Keefe JA: Gonadal steroid hormone receptors and sex differences in the hypothalamo-pituitary-adrenal axis. Horm Behav 1994, 28(4):464-476.

28. Yoshimura S, Sakamoto S, Kudo H, Sassa S, Kumai A, Okamoto R Sex-differences in adrenocortical responsiveness during development in rats. Steroids 2003, 68(5):439-445.

29. Young EA, Altemus M, Parkisonb V, Shastry S: Effects of estrogen antagonists and agonists on the ACTH response to restraint stress in female rats. Neuropsychopharmacology 2001, 25(6):881-891.

30. Kajantie E, Phillips DI: The effects of sex and hormonal status on the physiological response to acute psychosocial stress. Psychoneuroendocrino 2006, 31(2):151-178.

31. Kudielka BM, Buske-Kirschbaum A, Hellhammer DH, Kirschbaum C: HPA axis responses to laboratory psychosocial stress in healthy elderly adults, younger adults, and children: impact of age and gender. Psychoneuroendocrino 2004, 29(1):83-98.

32. Handa RJ, MCGivern RF: Gender and Stress. Encyclopedia of Stress. San Diego: Academic Press; 1999:196-204.

33. Albert $\mathrm{D}$, Jonik $\mathrm{R}$, Walsh M: Hormone-dependent aggression in male and female rats: experiential, hormonal, and neural foundations. Neurosci Biobehav Rev 1992, 16(2):177-192.

34. Van Der Meij L, Buun AP, Salvador A: Contact with attractive women affects the release of cortisol in men. Horm Behav 2010, 58(3):501-505.

35. Dai WG, Yin SY: Stuy of general trend of death in captive Forest musk deer. J Chengdu Univ Sci Tech 1990, 5:47-50.

36. Huber S, Palme R, Arnold W: Effects of season, sex, and sample collection on concentrations of fecal cortisol metabolites in red deer (Cervus elaphus). Gen Comp Endocr 2003, 130(1):48-54.

37. Lang DM, Wang YH, Hu DF, Ge XF: Evaluation of the storage of fecal samples of captive forest musk deer for steroid analysis. Sichuan J Zool 2011, 30(3):357-361.

38. Yu XJ, Hu DF, Jin XL, Ge XF, Yang LL, Zhao PP, Zhang Q: Non-invasive determination of fecal steroid hormones relating to conservation practice in giant panda (Ailuropoda melanoleuca). Anim Biol 2011, 61(3):335-347

\section{Submit your next manuscript to BioMed Central and take full advantage of:}

- Convenient online submission

- Thorough peer review

- No space constraints or color figure charges

- Immediate publication on acceptance

- Inclusion in PubMed, CAS, Scopus and Google Scholar

- Research which is freely available for redistribution 